\title{
Resources development and tourism environmental carrying capacity of ecotourism industry in Pingdingshan City, China
}

\author{
Yufeng Zhao* and Lei Jiao
}

\begin{abstract}
Background: Pingdingshan City has unique and rich ecotourism landscape. To realize the sustainable development of ecotourism industry in Pingdingshan and simultaneously achieve economic development and environmental protection in the development of ecotourism resources, literature analysis and field investigation methods were used to deeply explore the advantages and problems of Pingdingshan in the process of resources development in this study. Then, the indicator system of environmental carrying capacity of Pingdingshan was established and environmental carrying capacity was calculated to understand the local tourism environmental carrying capacity.

Results: The development of ecotourism resources in Pingdingshan has advantages of natural conditions, convenient transportation, and sound infrastructure, but there were also problems, such as insufficient resources protection and unscientific management system. After calculation, it was found that the environmental carrying capacity of ecotourism in Pingdingshan was overloaded.

Conclusion: This study reveals the development of the tourism industry in Pingdingshan and provides a basis for the future development of Pingdingshan tourism resources, which is beneficial to the sustainable development of the local ecotourism industry.
\end{abstract}

Keywords: Ecotourism resources, Environmental carrying capacity, Sustainable development, Resource-based city

\section{Introduction}

With the change of people's travel idea, ecotourism has developed rapidly. It has received widespread attention since its appearance. The ecotourism industry in Indonesia has gained a rapid development by virtue of its good ecotourism resources, indicating that the protection of ecotourism resources can effectively promote the sustainable development of the tourism industry (Hengky 2017). Siswanto (2015) concluded that the ecotourism industry had created more income for local residents and business owners and brought certain economic benefits to the local community. The development of ecotourism resources could raise people's awareness of environmental protection while increasing

\footnotetext{
* Correspondence: zhaoyfhn@yeah.net

Henan University of Urban Construction, Longxiang Avenue, Pingdingshan City 467000, Henan Province, China
}

economic income. Pingdingshan City is located in the south-central part of Henan Province, China. The geographical position is very unique, and the ecotourism resources are quite abundant. With the development of resources, the ecotourism industry in Pingdingshan City has developed rapidly, and many problems have arisen. Evaluating the carrying capacity of the ecological environment can effectively promote the development of ecotourism (Daneshvar and Sheybani 2011). Shi et al. (2015) calculated the carrying capacity of ecotourism in Shang-La County and found that the reasonable development of natural resources in Shang-La effectively promoted the long-term development of its ecotourism. Many resource-based cities have developed rapidly by virtue of abundant natural resources, but they also face problems of over-exploitation and resource exhaustion. As a resource-based city, ecotourism industry of 
Pingdingshan has developed rapidly, and its state of resource development needs to be paid attention to. However, the current research on tourism resources development and environmental carrying capacity of Pingdingshan has not been quite sufficient.

Based on the research on resource development of Pingdingshan City, this study established the evaluation system of ecotourism environmental carrying capacity of Pingdingshan and carried out corresponding evaluation to promote the sound and rapid development of ecotourism resources in Pingdingshan.

\section{Development status of tourism resources in Pingdingshan City}

Pingdingshan has been listed as a resource-based city by virtue of its rich and diversified natural resources. In addition to coal, steel, and other natural resources, Pingdingshan also has abundant tourism resources. Pingdingshan has superior geographical position and unique natural conditions. Its tourism resources are characterized by diverse contents, unique scenery, and concentrated resources. In recent years, the ecotourism industry of Pingdingshan has developed rapidly. The construction of scenic spots has almost covered all the important tourism resources of the Pingdingshan. The tourism resources are protected to drive the economic development in the process of development (Nuzula et al. 2017). However, the development of ecotourism resources in Pingdingshan also exists many problems. First of all, the destruction of ecotourism resources occurs frequently due to insufficient resources protection. Then, many management systems in the ecotourism industry are unscientific, resulting in the waste and inefficient use of many resources in the tourism industry, which cannot guarantee the sustainable development of tourism resources. In addition, the development and utilization of ecotourism resources in Pingdingshan is low. The lack of infrastructure is an important factor affecting the protection of tourism resources and low level of development and utilization, which is not conducive to the long-term development of tourist attractions.

\section{Calculation method of tourism environmental carrying capacity}

The ecotourism environmental carrying capacity refers to the acceptable number of tourists that can be accepted in a certain area, which can not only meet the needs of tourists and benefit the tourism industry, but also protect the environment and reduce the impact. In this study, the indicator system of environmental carrying capacity was constructed, and the calculation was made on that basis.

The system of ecotourism environmental carrying capacity consists of four parts: resource environmental carrying capacity, ecology environmental carrying capacity, psychology environmental carrying capacity, and tourism environmental carrying capacity. The value of ecotourism environmental carrying capacity is not the sum of the parts, but the minimum value of each part.

Resource environmental carrying capacity (RECC) refers to the number of tourists that can be reached in a region on the premise of realizing the time requirements of tourists, which is a major manifestation of environmental protection (Ye et al. 2016). Its expression is:

RECC $=($ daily turnover rate $\times$ total resource space $) /$ per capita basic space standard

Further calculations are based on the per capita area of the tourist area:

$$
\operatorname{RECC}=(S \times T) /(s \times t),
$$

where $S$ stands for tourist area $\left(\mathrm{m}^{2}\right), T$ stands for opening hours (h), $s$ stands for per capita area occupied by tourists $\left(\mathrm{m}^{2}\right)$, and $t$ stands for time required for a visitor to visit (h).

Ecology environmental carrying capacity (EECC) is the amount of tourism that a tourist area can bear without affecting the environment, which is expressed by the number of tourists. Its expression is:

$$
\mathrm{EECC}=\min (\mathrm{WECC}, \mathrm{AECC}, \mathrm{SWCC}),
$$

where WECC stands for water environmental carrying capacity, $\quad W E C C=$ daily sewage treatment level/daily sewage production per person, AECC stands for air environmental carrying capacity, $\mathrm{AECC}=\frac{S \times f}{s}$, where $S$ stands for tourist area $\left(\mathrm{m}^{2}\right), f$ stands for forest coverage ratio (\%), $s$ stands for per capita green areas $\left(\mathrm{m}^{2} /\right.$ person), and SWCC stands for solid waste carrying capacity, SWCC = total amount of daily disposed solid waste/per capita daily.

Selection criteria of indicators are different for tourist areas of different kinds or with different properties (Shen et al. 2017). According to the actual situation, water environmental capacity was regarded as the main aspect (Xu and Yan 2016).

Psychology environmental carrying capacity (PECC) includes the psychological capacity of residents and the psychological capacity of tourists in tourist areas (Zhang 2014). The psychological capacity of residents refers to the maximum number of tourists that residents of tourist areas can bear psychologically. The psychological carrying capacity of tourists refers to the maximum crowding condition that tourists can accept in the process of traveling. The result can be obtained through a questionnaire survey.

Tourism environmental carrying capacity (TECC) refers to the maximum number of tourists that the basic 
service facilities in the tourism area can afford (Zelenka and Kacetl 2014). Its expression is:

$$
\mathrm{TECC}=\min \left(\mathrm{TECC}_{1}, \mathrm{TECC}_{2}, \ldots \mathrm{TECC}_{i}\right),
$$

where $\mathrm{TECC}_{i}$ stands for economic burden part of supply amount $i, \mathrm{TECC}_{i}=\frac{S_{i}}{D_{i}}, S_{i}$ stands for daily supply amount of $i$ (amount/day), and $D_{i}$ stands for the per capita demand of $i$ (amount/person/day).

In conclusion, the calculation formula of ecotourism environmental carrying capacity is:

$$
\mathrm{ETEC}=\min (\text { RECC, EECC, PECC, TECC }) .
$$

\section{Calculation of tourism environmental carrying capacity of Pingdingshan City}

Firstly, RECC of Pingdingshan City was calculated. After checking the relevant literature, it was found that the effective tourist area of Pingdingshan City is about 972 $\mathrm{km}^{2}$, the open time is $12 \mathrm{~h}$, the per capita occupied area was $5 \mathrm{~m}^{2}$, and the time needed for visit is $12 \mathrm{~h}$. According to Eq. (1), we have:

$$
\operatorname{RECC}=(S \times T) /(s \times t)=194,400 .
$$

Then, EECC of Pingdingshan City was calculated. Taking water environmental carrying capacity (WECC) as an example, WECC = daily treatment level of sewage/ daily output of sewage $=3,360,000 / 60=56,000$.

Through checking the relevant literature and investigation, it was found that the psychology environmental carrying capacity of citizens was 90,000 person/day, the psychology environmental carrying capacity of tourists was 70,000 person/day, and the average value was 80,000 person/day.

The calculation of economy environmental bearing capacity was represented by traffic and accommodation:

$$
\begin{aligned}
\mathrm{TECC} & =\min \left(\mathrm{TECC}_{\text {traffic }}, \mathrm{TECC}_{\text {accommodation }}\right) \\
& =\min (76,000,78,647)=76,000 .
\end{aligned}
$$

The results of ecotourism environmental carrying capacity of Pingdingshan City were obtained, as shown in Table 1.

According to the minimum principle, the ecotourism environmental carrying capacity of Pingdingshan City was 20.44 million people each year, which was obtained by ecology environmental carrying capacity. It was found that ecology environmental carrying capacity could represent the ecotourism environmental carrying capacity, which was the most important and basic part in the indicator system. According to relevant reports, the number of tourists in Pingdingshan City has reached 20.96 million in 2016; hence, the ecotourism environment of Pingdingshan City was slightly overloaded.

In addition, the evaluation indicators of each carrying capacity module were further processed and analyzed, and 40 evaluation units were classified.

And then, nine evaluation factors were selected based on the data to establish the model, and evaluation indicators of two types were analyzed by using Statistical Product and Service Solutions (SPSS). The results are as follows.

The clustering and standardization results of resource environmental carrying capacity indicators in each scenic spot are shown in Fig. 1. In classification 1, the annual precipitation, river area ratio, and $>0{ }^{\circ} \mathrm{C}$ accumulated temperature were all negative values, indicating that the natural conditions of this type of scenic spot had natural advantages, and the corresponding resource environmental carrying capacity was high. In classification 2, the resource environmental carrying capacity was restricted by the river area, which was significantly different from the other four types of scenic spots, but it was also high. In classification 3, the resource environmental carrying capacity was restricted by the accumulated temperature. In classification 4 and 5 , only the proportion of vegetation area was negative and the others were positive, indicating that the resource environmental carrying capacity of these two types of regions was low (Table 2).

The clustering and standardization results of psychology environmental carrying capacity indicators in each scenic spot are shown in Fig. 2. In classification 1 and 2, the number of service industry units, domestic highway mileage, and settled ratio were all negative, indicating that the psychology environmental carrying capacity was very high. Pingdingshan City has a dense expressway

\begin{tabular}{|c|c|c|}
\hline $\begin{array}{l}\text { Types of tourism environmental } \\
\text { carrying capacity }\end{array}$ & $\begin{array}{l}\text { Daily average tourism environmental } \\
\text { carrying capacity }(10,000 \text { people) }\end{array}$ & $\begin{array}{l}\text { Annual average tourism environmental } \\
\text { carrying capacity }(10,000 \text { people })\end{array}$ \\
\hline Resource environmental carrying capacity & 19.44 & 7095.6 \\
\hline Ecology environmental carrying capacity & 5.6 & 2044 \\
\hline Psychology environmental carrying capacity & 8 & 2920 \\
\hline Economy environmental carrying capacity & 7.6 & 2774 \\
\hline
\end{tabular}
network and 400-km-long railway, and there are three airports around. Convenient transportation is one of the great advantages of developing tourism in Pingdingshan

Table 1 The calculation result of the ecotourism environmental carrying capacity in Pingdingshan City 


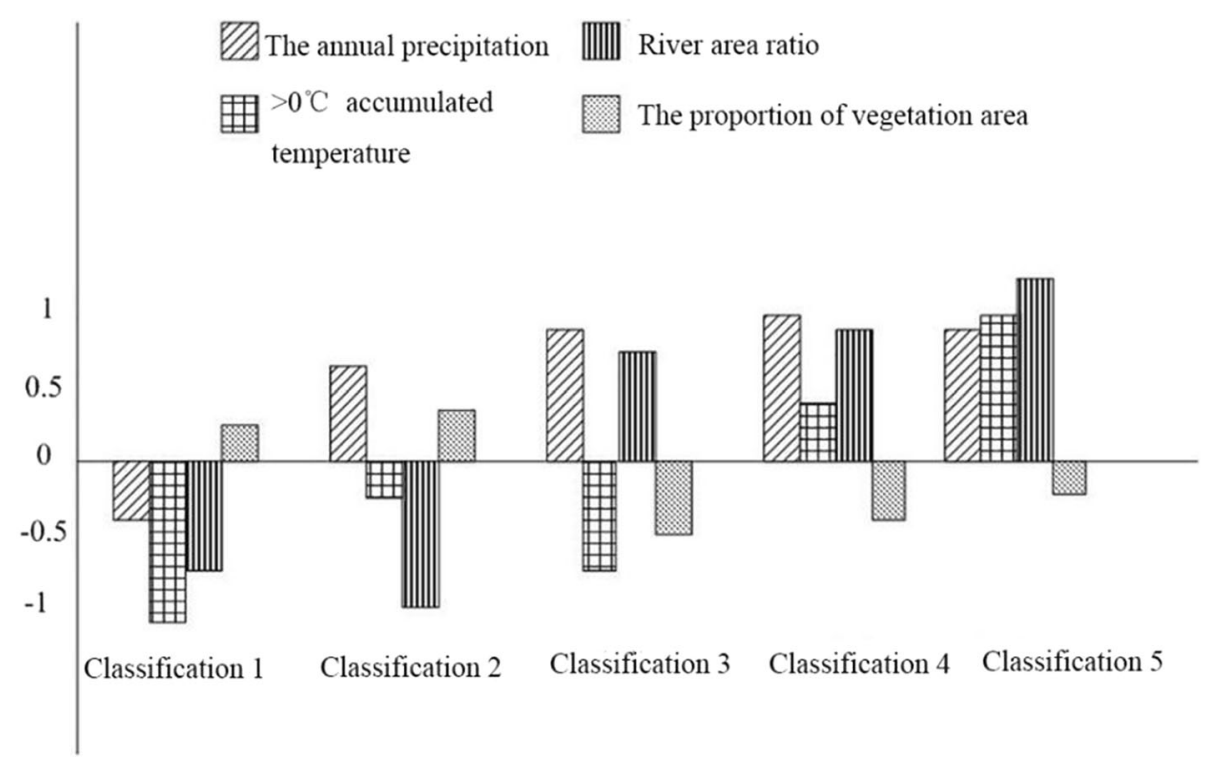

Fig. 1 Standard value of resource environmental carrying capacity clustering results

City. The standardized values of classification 3 and 4 were both relatively small, and the psychology environmental carrying capacity of them was smaller than that of classification 5. Moreover, the two kinds of areas could be planned together because of the similar values of the relevant indicators. The indicators in classification 5 were relatively large, indicating that the psychology environmental carrying capacity was low, and it was likely to be restricted by ecological resettlement.

\section{Discussion and conclusion}

The development of resource-based cities is based on resources. The excessive exploitation of resources will lead the development of cities to decline gradually. In order to guide the scientific development of tourism industry in Pingdingshan City, the local government should attach great importance to the development of local tourism industry and provide relatively sufficient funds for the construction of scenic spots. Convenient transportation and relatively sufficient supply of water and electric are both the development advantages of ecotourism industry in Pingdingshan City, but the resident level of tourists are far from being up to the required standards. In addition, due to the late and rapid development of some scenic spots in Pingdingshan City and under the effects of local conditions, the environmental pollution of tourist attractions is prominent. The relevant infrastructure of the scenic spots is generally backward, which directly increases the pollution of scenic spots. With the rapid growth of industrial and domestic pollutants and the backwardness of treatment facilities in Pingdingshan City, environmental pollution will gradually be serious and the remaining environmental capacity will be smaller and smaller (Solís et al. 2014). The solid waste of scenic areas in Pingdingshan City will be uniformly transported to the outside of the scenic spot for unified treatment, so the solid waste carrying capacity was relatively large. Therefore, it is necessary to focus on solving these two problems, rationally allocate tourism resources, and promote the long-term development of the ecotourism industry. The ecotourism industry in Pingdingshan City is developing rapidly. In order to achieve better and long-term tourism development, it is necessary to strengthen the protection of resources and improve the scientific management of the system to solve problems existing in the development. Due to the large scenic area of Pingdingshan City, the rich types of ecotourism resources, and different opening degree of each scenic spot, there exist some uncertainties in the ecological carrying capacity of scenic areas in Pingdingshan City. According to the calculation results, the resource environmental carrying capacity, tourism environmental carrying capacity, and psychology

Table 2 Classification and grade of each indicator's carrying capacity

\begin{tabular}{llllll}
\hline Classification & Classification 1 & Classification 2 & Classification 3 & Classification 4 & Classification 5 \\
\hline Grade of carrying capacity & High & Relatively high & Medium & Relatively low & Low \\
\hline
\end{tabular}




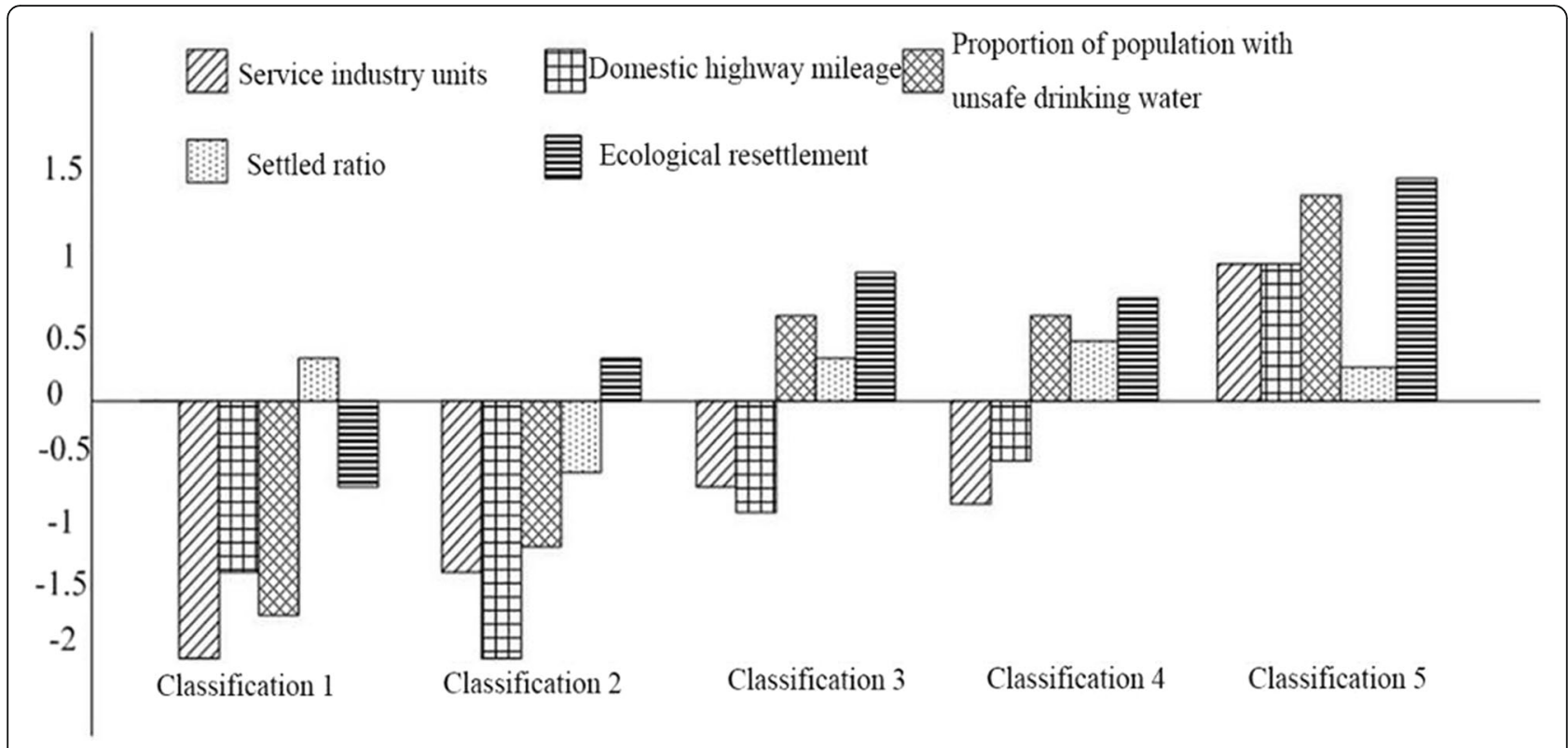

Fig. 2 Standard value of psychology environmental carrying capacity clustering results

environmental carrying capacity have not reached the limit, and more tourists can be accepted, but the ecology environmental carrying capacity has been seriously overloaded, resulting in overall overload. Therefore, the key to the development of tourism industry in Pingdingshan City is to improve the ecology environmental carrying capacity (Cheng et al. 2016).

Under the premise of adhering to the necessary principles, the development of tourism industry in Pingdingshan needs to take corresponding measures for the existing problems. By establishing an indicator system of ecotourism environmental carrying capacity with four levels and nine evaluation factors, this study analyzed from four aspects and found that the ecology environmental carrying capacity of Pingdingshan City has seriously affected the development of the tourism industry and positive measures need to be taken to improve it. The study results provide a basis for the development of tourism industry resources, which is conducive to the sustainable development of resource-based cities and has reference values for the further development of the tourism industry in Pingdingshan City.

\section{Acknowledgements}

Not applicable.

\section{Funding}

This study was supported by Henan Provincial Government Decision Making Research (project number: 2012B116).

\section{Authors' contributions}

YFZ analyzed the low-carbon tourism mode, looked up the advantages of developing low-carbon tourism in natural conditions and tourism resources in Guizhou, estimated the carbon emissions of Guizhou tourism industry in 2011-2015, discussed and analyzed the results together with $L$, and drafted the article. $L$ assisted YFZ to collect the data needed for estimating the carbon emissions of Guizhou tourism industry from 2011 to 2015 and calculate and analyze them. He put forward the main problems existing in the development of low-carbon tourism; put forward corresponding suggestions from the perspectives of government, tourism enterprises, and tourists; and perfected the article. Both authors read and approved the final manuscript.

Ethics approval and consent to participate

Not applicable.

\section{Consent for publication}

Not applicable.

\section{Competing interests}

The authors declare that they have no competing interests.

\section{Publisher's Note}

Springer Nature remains neutral with regard to jurisdictional claims in published maps and institutional affiliations.

Received: 13 November 2018 Accepted: 21 February 2019

Published online: 14 March 2019

\section{References}

Cheng J, Zhou K, Chen D, Fan J (2016) Evaluation and analysis of provincial differences in resources and environment carrying capacity in China. Chin Geogr Sci 26(4):539-549.

Daneshvar MRM, Sheybani S (2011) GIS based evaluation of ecotourism zonation using ecological carrying capacity model (Study area: Kalat county, north of Khorasan-e-Razavi province) (In Persian). International Conference on Tourism Management and Sustainable Development, Marvdasht, pp 1-17. Hengky SH (2017) Probing coastal eco-tourism in Pasir Putih Beach, Indonesia. Bus Manag Horiz 5(1):1-11. 
Nuzula NI, Armono HD, Rosyid DM (2017) Management of Baluran National Park resources for coastal ecotourism based on suitability and carrying capacity. Appl Mech Mater 862:161-167.

Shen SY, Niu EX, Meng B (2017) Evaluation of ecological environment carrying capacity in coastal waters of Liaoning based on Grey relation. J Dalian Maritime Univ 43(3):112-118.

Shi LY, Zhao HB, Li YL, Ma H, Yang SC, Wang HW (2015) Evaluation of Shangri-La County's tourism resources and ecotourism carrying capacity. Int J Sust Dev World 2(2):103-109.

Siswanto A (2015) Eco-tourism development strategy Balurannational Park in the regency of Situbondo, East Java, Indonesia. Int J Eval Res Educ 4(4):185.

Solís D, Corral JD, Perruso L, Agar JJ (2014) Evaluating the impact of individual fishing quotas (IFQs) on the technical efficiency and composition of the US Gulf of Mexico red snapper commercial fishing fleet. Food Policy 46(6):74-83.

Xu ZL, Yan W (2016) Carrying capacity of water environment in public tourism resources based on matter-element model. Ecol Econ 3:296-300.

Ye W, Xu X, Wang H, Wang H, Yang H, Yang Z (2016) Quantitative assessment of resources and environmental carrying capacity in the northwest temperate continental climate ecotope of China. Environ Earth Sci 75(10):868

Zelenka J, Kacetl J (2014) The concept of carrying capacity in tourism. Amfiteatru Econ 16(36):641-654.

Zhang B (2014) A research on residents' social-psychological carrying capacity of tourism destinations: a case study on Asakusa area, Tokyo, Japan. Tour Tribune 29(12):55-65.

\section{Submit your manuscript to a SpringerOpen ${ }^{\circ}$ journal and benefit from:}

- Convenient online submission

- Rigorous peer review

- Open access: articles freely available online

- High visibility within the field

- Retaining the copyright to your article

Submit your next manuscript at $\boldsymbol{\nabla}$ springeropen.com 